\title{
TMS Members Receive AAAS Fellow Distinction; Welcome New Members
}

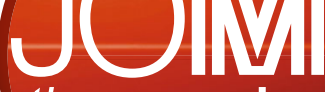

themagazine

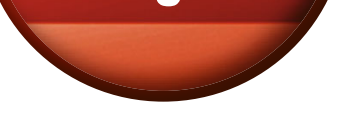

\section{member news}

Share the good news about your professional accomplishments! Contact Kaitlin Calva, JOM Magazine Managing Editor, atkcalva@tms. org. Please note that only news submitted by current TMS members will be considered.

\section{Eight TMS Members Honored by AAAS}

Congratulations to the following TMS members for being honored by the American Association for the Advancement of Science (AAAS) as 2020 Fellows. According to AAAS, "Fellows are a distinguished cadre of scientists, engineers, and innovators who have been recognized for their achievements across disciplines." They were elected in October 2020 and chosen out of 489 individuals worldwide, in 24 different AAAS section affiliations.

\section{Section on Chemistry \\ Paul V. Braun \\ University of Illinois at \\ Urbana-Champaign \\ TMS member since 2013}

\section{Jiaxing Huang}

Northwestern University

TMS member since 2012

\section{Section on Engineering}

L. Catherine Brinson

Duke University

TMS member since 2002

Kristen P. Constant

Iowa State University

TMS member since 2015

Ju Li

Massachusetts Institute of Technology

TMS member since 2003
Uday B. Pal

Boston University

TMS member since 1992, recipient of the 2015 Extraction \& Processing Division Distinguished Lecture Award, and co-editor-in-chief of the Journal of Sustainable Metallurgy

Robert O. Ritchie

University of California, Berkeley TMS member since 1976, recipient of the 2020 William D. Nix Award, 2017 Morris Cohen Award, 2010 Institute of Metals/ Robert Franklin Mehl Award, and 2004 TMS Fellow

\section{Section on Societal Impacts of Science and Engineering Oladele (Dele) A. Ogunseitan University of California, Irvine, TMS member since 2005}

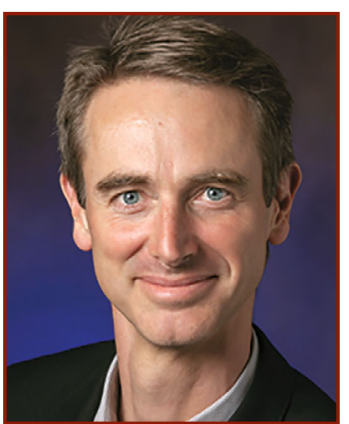

Paul V. Braun

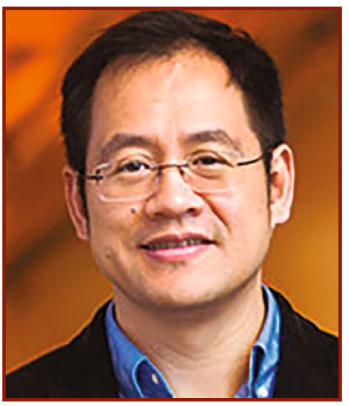

Ju Li

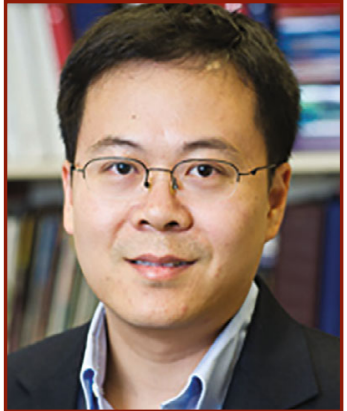

Jiaxing Huang

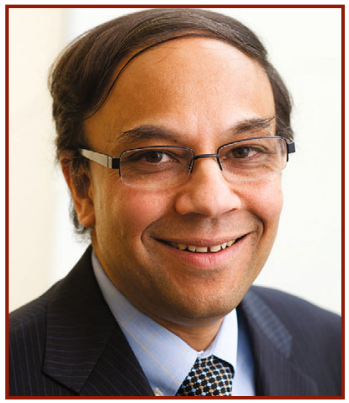

Uday B. Pal

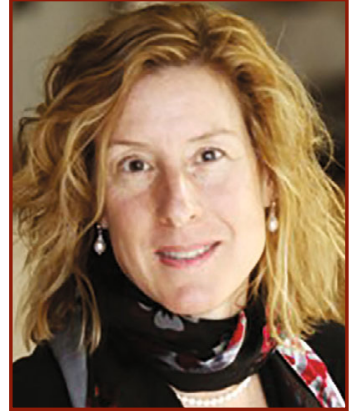

\section{Catherine Brinson}

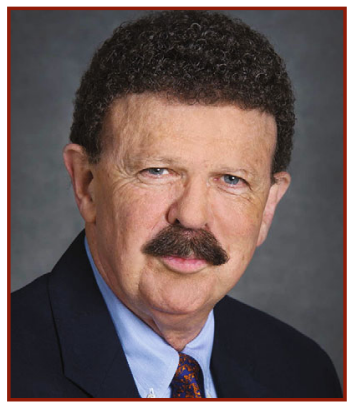

Robert O. Ritchie

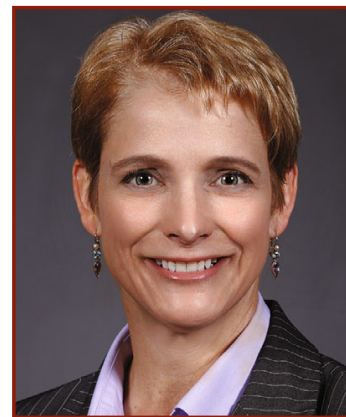

Kristen P. Constant

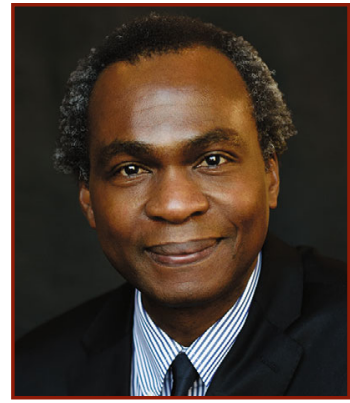

Oladele (Dele) A. Ogunseitan 


\section{TMS Welcomes New Members}

The TMS Board of Directors approved professional membership for the following individuals at its December 2020 meeting. Please join us in congratulating and welcoming them to all the privileges and benefits of TMS membership.

Aceves, Maureen; Oxford University, United Kingdom

Al-Lehyani, Ibrahim; King Abdulaziz University, Saudi Arabia

Amini, Shahram; Pulse Technologies Inc., United States

Andermann, Lawrence J.; Suez, United States

Apena, Azeez; United States

Arai, Noriaki; QuesTek Innovations LLC, United States

Beach, Elvin; The Ohio State University, United States

Birnbaum, Peter; Chemnitz University of Technology, Germany

Brueck, Ekkes; Delft University of Technology, Netherlands

Chan, Andrew; ALD Vacuum Technologies North America Inc. United States

Chen, Yi-Sheng; The University of Sydney, Australia

Choi, Hongseok; Clemson University, United States

Colpitts, Tanner D.; United States

Cristante, Angelo; United States

D'Abreu, Jose Carlos; Catholic University, Brazil

Dos Santos, Igor Cuzzuol; AMG Brasil, Brazil

Dowdle, John; Old Hickory Clay Company, United States
Fu, Wentao; United States

Fuerst, Jacob D.; United States

Gagnon, Jessie; Laval University, Canada

Gupta, Ankur; Indian Institute of Technology Jodhpur, India

Holota, Radek; University of West Bohemia, Czech Republic

House, Stephen D.; University of Pittsburgh, United States

Hunert, Daniela; Germany

Jacobsohn, Luiz G.; Clemson University, United States

Jain, Vipin; National Physical Laboratory, India

Kapoor, Monica; Novelis, United States

Khalaj, Omid; University of West Bohemia, Czech Republic

Klenam, Desmond E.P.; South Africa

Kolel-Veetil, Manoj; Naval Research Laboratory, United States

Korotov, Anne-Sophie; United Kingdom

Koucky, Vaclav; University of West Bohemia, Czech Republic

Kua, Harn-wei; National University of Singapore, Singapore

Lin, Jeffrey D.; QuesTek Innovations LLC, United States

Macha, John; United States

Massie, Grant Nicol; Gates Power Transmission Ltd., United Kingdom
Meng, Fan; QuesTek Innovations LLC, United States

Porter, Eric l.; University of Alberta, Canada

Romani, Nadia; Rio Tinto, Canada

Santala, Melissa K.; Oregon State University, United States

Schaadt, Steven T.; Howmet Aerospace, United States

Sharma, Prince; India

Shu, Wenya; Virginia Polytechnic Institute and State University, United States

Skala, Jiri; University of West Bohemia, Czech Republic

Sobotova, Lenka; University of West Bohemia, Czech Republic

Sohrabi, Sajad; Islamic Republic of Iran

Sorkin Samuel; QuesTek Innovations LLC, United States

Souza, Flavio; United States

Stadler, Ctibor; University of West Bohemia, Czech Republic

Thamizhirai, Selvan; United Kingdom

Unruh, Bryan L.; NuWay Solutions LLC, United States

Wilkinson, Mark; United Kingdom

Yu, XiaoXiang; Novelis Inc., United States

*Membership grade recommendations are based on a review of credentials provided by the individuals.

These credentials are taken on the honor system and not independently verified, except by exception. 